\title{
PAPEL HIGIÉNICO, POLLOS, FARMACIAS: ¿COLUSIÓN HORIZONTAL $O$ VERTICAL?
}

Por Andrea Butelmann, Ph. D Economía, Economía Aplicada a Políticas Públicas UAH.

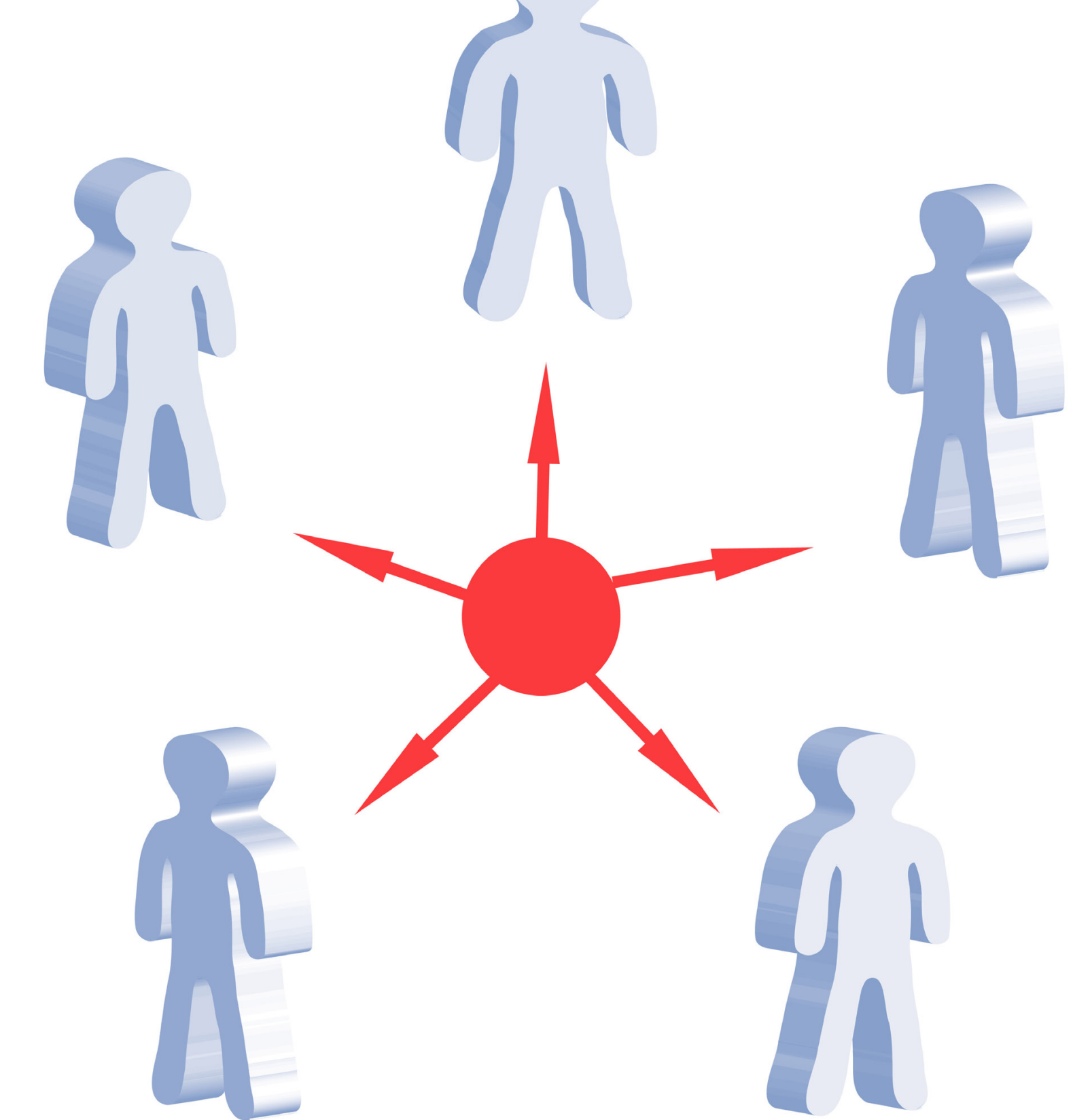

Cuando hay que repartirse rentas, los actores que no estan en la mesa de nede las colusiones los que están sentados son los proveedores $y$ los minoristas los consumidores no están invitados a ta mesa. La solución, sin embargo, la aporta la competencia para ganarse al invitado clave para que la fiesta prosiga, pero zy si no hay competencia? ¿Qué pasa si no es necesario seducir al consumidor con menores precios?

La pregunta es entonces qué ha pasado en el sector minorista. La respuesta es simpley nos pasa a todos. la tecnologia. Si antes el comercio era una actividad de menor escala, de emprendimientos familiares, con uno o dos locales -porque más era imposible de admistrar por un individuo-, una empresa pueda administrar cientos de locales $y$ aumentar la eficiencia en todos los procesos. En particular, ha permitido el acopio en sitios de menor valor inmobiliario $y$ la distribucion centralizada a los puntos de venta. Hasta acá todo bien, tecnología permite ganar eficiencias y reducir costos, nada nuevo bajo el sol.

La otra cara de la moneda, sin embargo, es que por el aporte de la tecnologia, las empresas que pueden sobrevivir son más grandes $y$, por supuesto, menos. Y los costos de la concentración son la reducción en el grado de competencia, ya sea por Iusión tácita que no es ilegal. En efecto, al ser pocas las empresas en el mercado cada una tiene incentivos a morigerar su intensidad competitiva aunque no se pongan explicitamente de acuerdo con el resto de los actores.

El tema de este articulo es cómo, al haber menos competencia a nivel minorista se afecta tambien la competencia a nive de proveedores. Basicamente, la idea que hay una sola renta a repartir entre proveedores y minoristas: la diferencia entre los costos de producir y distribuiry el precio que paga el consumidor. Si el precio que paga el consumidor baja, la renta será me- nor y perderán ambos. Asi a los proveedomás competencia naya que si baja el precio final - sobre todo en bienes de primera necesidad con demandas inelásticas- ni siquiera venderán más y, además, habrá menos rentas a repartir con el minorista. Del mismo modo, a cada despertaria la competencia entre minoristas y, para no perder Clientes, bajaria los repartir.

En este juego las marcas propias juegan un dobre roli los sumcas propias juegan frecer productos en quercados pueden renta con el proveedor $y$ además, pueden mantener a rava el poder de negociación de estos al momento de repartirse la renta de los productos producidos por ellos

De ahi la pregunta inicial sobre si la colusión es horizontal o vertical. Es importante recordar que en el caso de la colusión de funon los laboratorios los que coordinaron las alzas de precios entre las farmacias, no analizaremos si lo hicieron voluntariamente o presionados, pero precios entre elas ya quen si prosera de competencia iban a verse presionia bajar los precios mayoristas.

La idea de que a los minoristas, en un entren nuevos proveedores (aunque tengan menores costos) está brillantemente expuesta en el artículo de los economistas Asker y Bar-Isaac en el American Economic Review de enero de 2014. Además de a teoria, en el artículo se resume lo que ha sido la discusión sobre estos temas en la jurisprudencia estadounidense y la teoria Enomica que lleva casi un siglo.

En efecto, durante casi 100 años estuprecios minidos en Estados Unidos los tuir una forma de colusión vertical. Asi se nula la competencia por precio en el retal

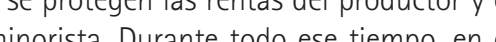
sentado varias teorías que explican que, en determinadas circunstancias, los precios minimos de reventa pueden ser eficientes cuando el minorista debe cliente sobre las caracteristicas del proatro local lo venden más barato aprovechándose de la información obtenida por el cliente en el local que tiene vendedores

existen pros y (a) azón ie sopesar las razones de eficiencia con los efectos anticompetitivos.

Si bien lo anterior es ilustrativo de los peligros que hay en la repartición de renas entre proveedores y minoristas, es claro que los precios minimos de reventa no so vor mucho que se prohiban algunos do Demás está poir qun les incentivos a no pomodar entrada a nuevos proveedores por parte de los minoristas no sólo mantene los precios altos para el consumidor sino que además no incentiva el emprendiiento y la innovación Por ello, es necesaro un debate sobre hasta qué medida espor sobre ta competencia en mercados tan laves para el bienestar social y la productividad.

Es ilustrativo de esta discusión el hecho Es . (a) popular habia abierto el paso a sábado 12 de diciembre).

"Sobre el Oportunismo en los Negocios: del Benefio Legitimo a la Kairospatta" The 